\title{
A Thorough Analysis of the Current State of Cancer Education in Medical Schools and Application of Experimental Teaching Techniques and Their Efficacy
}

This article was published in the following Dove Press journal:

Advances in Medical Education and Practice

\author{
Andrew Klufas' \\ Grace Shin' \\ Ryan Raphael' \\ Suzanne C Sarfaty ${ }^{2}$ \\ Ariel E Hirsch ${ }^{3,4}$ \\ 'Boston University School of Medicine, \\ Boston, MA, USA; ${ }^{2}$ Department of \\ Medicine, Boston University School of \\ Medicine, Boston, MA, USA; \\ ${ }^{3}$ Department of Radiation Oncology, \\ Boston Medical Center, Boston, MA, \\ USA; ${ }^{4}$ Department of Radiation \\ Oncology, Boston University School of \\ Medicine, Boston, MA, USA
}

\begin{abstract}
Newly diagnosed cases of cancer are expected to double by the year 2040 . Although many different oncology teaching initiatives have been implemented, many students continue to report uncertainty when dealing with patients with cancer. Through this review, we aim to find the most effective teaching methods to better prepare future physicians. Papers studying different methods of teaching oncology were identified through a thorough review of specific electronic databases. Each study was analyzed and sorted into one of ten unique categories created by the authors specifically for this review. If portions of the study fit into multiple categories, relevant results would be analyzed in all applicable areas. Additionally, papers were separated and analyzed by country of origin, preclinical or clinical interventional basis, and quantitative versus qualitative form of statistical analysis. A total of 115 papers from 26 different countries and regions were included in the final analysis. $91.4 \%$ of papers analyzing Lecture and Small Group Discussions indicated a positive impact. $97.1 \%$ of papers analyzing Clinical Practice and Simulation indicated a positive impact. $100 \%$ of papers analyzing Early Experience and Mentorship, Summer Programs and Voluntary Electives, use of Multidisciplinary Teams, and Role Play stated that these methods had a positive impact. $50 \%$ of papers analyzing Computer/Web Based Programs indicated a positive impact. Clinical Practice and Simulation, Role Play, Summer/Elective Programs and interventions involving Multidisciplinary Team Work all appeared to be most effective. Intensive Block Programs, Didactic Lectures/Small Group Discussions, and Computer/Web Based Education tools as a whole were variable. General Review papers showed continued variability in domestic and international oncology curricula. Incorporation of effective teaching interventions should be highly considered in the future creation of standardized oncology curricula in order to best prepare the next generation of physicians. Future studies could explore the differing efficacies of teaching interventions in the postgraduate versus graduate realms.
\end{abstract}

Keywords: oncology, medical student, intervention, curriculum, clinical, preclinical

\section{Introduction}

Cancer accounts for approximately 1 in every 6 deaths worldwide and is the second leading cause of death overall. ${ }^{1}$ Furthermore, the World Health Organization reports 17 million newly diagnosed cases in 2018, with this figure estimated to increase to 27.5 million cases by the year $2040 .{ }^{2,3}$ With the rise in prevalence of both cancer diagnoses and deaths in the future, it is imperative that practicing physicians be able to diagnose and address basic cancer patient needs, regardless of their position as a primary provider or specialist.
Correspondence: Andrew Klufas 233 Northampton Street, Apartment I, Boston, MA 02118, USA

$\mathrm{Tel}+\mathrm{I}$ 40I 489 309।

Email aklufas@bu.edu 
The role of developing these skills falls to the schools around the world who specialize in teaching medicine and training the physicians of the future. Many curricula and programs specifically designed to instruct students in both the basic and clinical sciences, as well as professional and clinical competency, have been proposed. More traditional classroom based approaches with a focus on lectures and case discussions have been implemented in the United States. ${ }^{4}$ Week-long summer courses focusing on intensive improvement of grasp of oncology related topics have been held for over two decades in Europe. ${ }^{5}$ Standardized oncology curricula have even been proposed for Australian medical schools, however adoption is lacking nationwide. $^{6}$

Different initiatives to teach oncology have been shown to be effective in several areas of cancer survivorship care. ${ }^{7}$ Despite these efforts, many students continue to report unease and uncertainty with their knowledge and abilities. ${ }^{8-10}$ Additionally, surveys reveal underemphasized and fragmented oncology education with wide variability in content and structure between medical schools, indicating that reform is needed within just the United States alone. ${ }^{11}$

Due to the wide variety of topics and systems that need to be covered in order to comprehensively teach Oncology, it is a difficult subject to approach. The outline of recommended core competencies and curriculum for cancer education, including basic sciences, clinical concepts, and social and emotional issues, is too vast to effectively disseminate to medical students. ${ }^{12}$ Although research has been conducted to find which topics are most relevant, little has been uncovered with regard to how to best teach these concepts. ${ }^{4}$ Without effective presentation and retention, students will not be able to apply what they have learned to best care for our ever growing cancer population.

This literature review aims to conduct a thorough global review on the current state of oncology education and analyze which methods result in significantly better student learning and clinical application. Through investigation of differing teaching methods we hope to gain insight into their perceived versus supported effectivity as well as practicality in future application.

\section{Methods}

Studies were identified through a thorough review of these specific electronic databases: PubMed, MEDLINE, Embase, and MedEdPORTAL. Searches were conducted using the following key phrases: "oncology", "medical education", “curriculum", "intervention", "medical student", "clinical", "preclinical", and "teaching." Each paper was individually analyzed for the presence of relevant oncologic teaching interventions involving all medical students and a publication date within the last thirty years. This date range was chosen in order to encompass a wide variety of experimental teaching methods and expand analysis of oncology education in countries with a paucity of relevant publications. Interventions involving residents, fellows, and physicians were not included. No specific journals were excluded from this study. Only publications written in English were accepted. Type of analysis of intervention (ie, qualitative vs quantitative) was not a criteria for exclusion. Each paper was sorted into one of ten unique categories created by the authors specifically for this study. If portions of a study fit into multiple categories, relevant results would be analyzed in all applicable areas.

The categories are listed below along with a brief summary expanding upon their criteria for inclusion.

\section{Lectures and Small Group Learning}

(a) Studies which analyzed the use of lecture and small group learning to teach oncology. These more traditional curricular components may have been tweaked in structure, presentation, area of focus, or balance in distribution of small versus large group discussion.

\section{Clinical Practice and Simulation}

(b) Studies which analyzed student interaction with standardized oncology patients, physicians playing the role of a cancer patient, or exposure to real life clinical duties and patients relative to recorded improvements in medical student skills and confidence and effect on future patient interactions.

\section{Summer Programs and Elective}

(c) Studies which analyzed programs offered to students as either a standalone summer program or complementary elective to the normal curriculum. These were nearly all voluntary in nature and focused on providing additional exposure to the domain of oncology through various methods including research, traditional classroom time, or courses aimed to improve empathy. 


\section{Computer Programs}

(d) Studies which analyzed computer or internet-based methods of learning. These digital learning tools were tested to see if understanding and performance of different oncology topics would be enhanced through non-traditional avenues. Multiple methods were considered including, but not limited to, online lectures, web based e-modules, educational games, and patient simulations.

\section{Early Experience Programs and Mentorship}

(e) Studies which analyzed early exposure to oncology via clubs and various other programs and oncologist-based mentorship and its effect on eventual choice of specialty.

\section{Blocked versus Integrated Curriculum}

(f) Studies which analyzed the use of concentrated blocks of time to teach oncology. Papers were analyzed based on total hours taught and whether it was specifically blocked out or integrated throughout a curriculum. Intensive summer courses were also analyzed however these were part of pre-existing curricula rather than voluntary programs evaluated in the Summer Programs/Electives category above.

\section{Role Play}

(g) Studies which analyzed experiences empowering students to take on the role of a patient or physician in the healthcare setting with other students. Although similar to the Clinical Practice/Simulation category, the Role Play classification focused on empathizing with the patient by simulating their experience with solely medical students taking on these roles.

\section{Multidisciplinary Teams}

(h) Studies which analyzed the effect of multidisciplinary teamwork on student confidence and clinical ability in the oncology setting. Exposure to multiple different specialties in the classroom as well as clinical based settings were analyzed with a focus on perceived improvement in medical student competency.

\section{Other}

(a) Studies whose unique interventions did not fit neatly into one of the groups listed above.
Although this section did not allow for direct comparison of interventions between one another, nonclassical teaching tactics with enough supportive evidence may be of benefit to students.

\section{General Review}

(b) This category was designated to papers whose main focus was not to present a specific change in intervention, but rather to highlight the most recent state of oncology curricula around the world. Studies here focused on analyzing flaws in currently implemented systems, discussion of possible improvements, and student and faculty satisfaction with the existing state of their educational programs.

Additionally, papers were analyzed and separated by country of origin, or region of focus if the study covered multiple countries, in order to identify location of teaching intervention and most recent curriculum structure. In scenarios where multiple countries contributed to an intervention, the country with the most direct correlation to the study was indicated as the primary country of origin. If not possible, all countries were given credit and included in the final analysis. Studies were classified as "Other and International" when not directly tied to a specific country of interest or organization.

Studies were also organized by a "Preclinical" or "Clinical" classification. "Preclinical" interventions were defined as those changes which were implemented during the equivalent Basic or Clinical Science years of a respective country's medical curriculum. "Clinical" interventions were defined as experimental conditions which occurred beyond this point of education or the equivalent thereof. If a paper presented or discussed an intervention which met both criteria, the intervention in question was added to both categories.

Within each category, trends were initially analyzed as a whole with no regard to type of statistical analysis (quantitative) or lack thereof (qualitative). The total number of papers were presented, as well as a percentage of those in favor of the intervention. Additionally, inconclusive papers were included as well in order to convey variable effectivity of certain educational trials. Furthermore, each applicable category had its respective studies separated into groups depending on the qualitative or quantitative nature of analysis. The quantitative group included papers which have had statistical analysis conducted upon the original results by the authors of the study. Qualitative included numbered or free- 
response surveys, student commentary and testimonials, or numerical data without statistical analysis. Effectivity of qualitatively analyzed interventions were determined via original author conclusions or situationally due to the wide and varying analyses used in this area. Conflicting opinions were resolved via author discussion by determining whether the source also used quantitative analysis and by determining if a majority of the data was positive or negative in nature.

A qualitative analysis was performed to identify the teaching interventions with the greatest impact. General trends were analyzed and interventions were distributed into one of three categories: "Highly Effective", "Moderately Effective", and "Ineffective." These categories were discussed as whole parts with analysis of their relationships to one another, viability of application, and practicality in a standardized curriculum.

\section{Results}

115 papers from 26 different countries and regions were included in the final analysis. The United States comprised $61.7 \%$ of the analysis pool. European countries contributed $27.0 \%$ of studies collected. The United Kingdom accounted for 7.8\%. Australia contributed $6.1 \%$ with New Zealand accounting for $1.7 \%$. Canada supplied $4.3 \%$ of total papers. South America contributed $0.9 \%$ while Asia and The Middle East provided $5.2 \%$ (Table 1).

Out of the 115 studies analyzed, 82 of these were categorized as "Preclinical" while 63 demonstrated "Clinical" intervention. 22 publications were found to have interventions fitting into both categories (Figure 1).

The studies found were analyzed and distributed into the unique interventional categories defined above (Table 2).

\section{Lectures and Small Group Learning}

Out of the 28 papers written about Lecture and Small Group Discussions, 89.3\% (25) stated that these methods had a positive impact and $10.7 \%$ (3) stated that there was a negative impact in comparison to other teaching methods. $21.4 \%$ (6) of these papers analyzed preexisting or experimental methods qualitatively, 71.4\% (20) analyzed their data quantitatively, and $6.4 \%$ (2) used both forms of analysis.

Lectures were found to take various forms throughout the papers analyzed. Positive papers found that seminars dealing with the psychological and social impact of cancer on patients and their families were rated positively by
Table I Distribution of Studies Based on Country or Region of Origin

\begin{tabular}{|c|c|c|c|}
\hline \multicolumn{2}{|l|}{ North America } & \multicolumn{2}{|l|}{ Europe } \\
\hline United States & 71 & United Kingdom & 9 \\
\hline Canada & 5 & The Netherlands & 4 \\
\hline \multicolumn{2}{|l|}{ Oceania } & Austria & 3 \\
\hline Australia & 7 & Lithuania & 2 \\
\hline New Zealand & 2 & Poland & 2 \\
\hline \multicolumn{2}{|l|}{ Asia and the Middle East } & Spain & 2 \\
\hline China & 2 & Switzerland & 2 \\
\hline India & I & Finland & I \\
\hline Israel & 1 & Germany & I \\
\hline Japan & I & Greece & I \\
\hline Thailand & I & Italy & I \\
\hline \multicolumn{2}{|l|}{ South America } & Norway & I \\
\hline Brazil & I & Portugal & I \\
\hline \multicolumn{2}{|l|}{ Other } & Sweden & I \\
\hline \multirow[t]{2}{*}{ Other and International } & \multirow[t]{2}{*}{3} & \multicolumn{2}{|l|}{ Africa } \\
\hline & & Egypt & 2 \\
\hline
\end{tabular}

students. ${ }^{13}$ Pre- and post-lecture student knowledge in a wide variety of other topics significantly improved as well, including management of breast and testicular cancer, as well as ability to identify various cancer risk factors, prevention strategies, and warning signs. ${ }^{14-16}$ This same trend was also seen in self-reported knowledge after lectures focused on delivering bad news and development of positive attitudes towards holistic and complementary treatment methods when used alongside more traditional treatment plans. ${ }^{17,18}$

$100 \%$ of the papers looking at the use of didactic lectures within oncology and radiation oncology clerkships were positive in all reported metrics. Hirsch et al showed significant improvement in pre- and post-test exam scores in radiation oncology, as well as breast, prostate, and general cancer management knowledge. ${ }^{19-21}$ There was no significant improvement in cancer staging knowledge. ${ }^{22}$

Qualitatively 88\% of fourth year students reported motivation to learn more about radiation oncology and $83 \%$ reported a better understanding of cancer care after an increased number of lectures. ${ }^{23}$ In comparison, Agarwal et al observed that $68.4 \%$ of students thought that lectures effectively contributed to their overall education. ${ }^{9}$ Further 


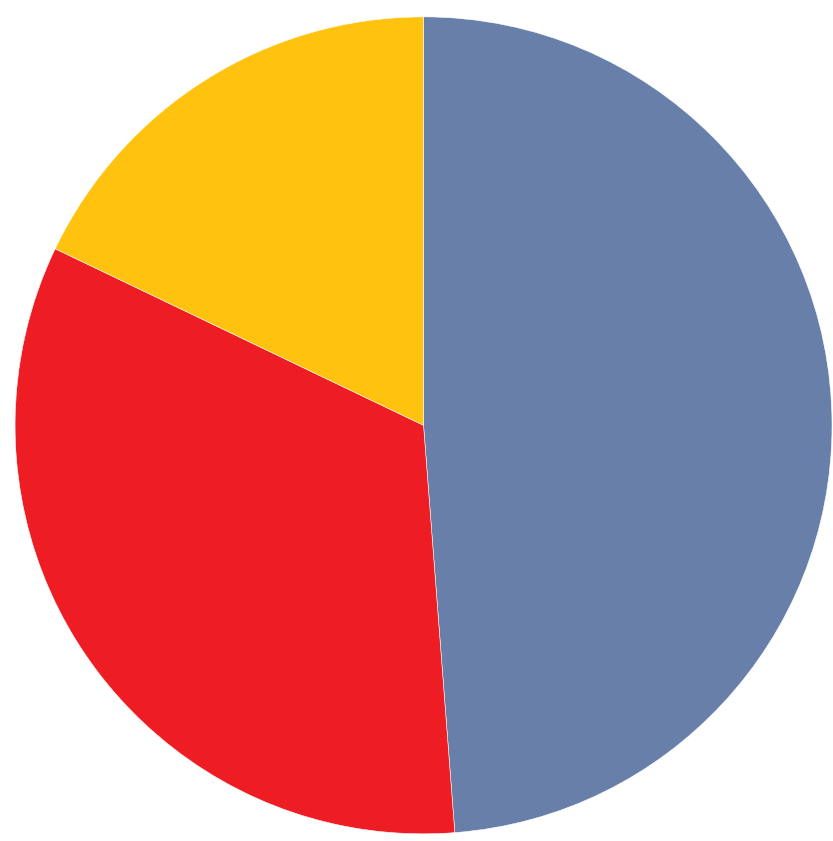

Figure I Distribution of studies based on preclinical versus clinical intervention. Solely preclinical interventions are shown in blue and solely clinical interventions are shown in red. Publications with interventions in both categories are shown in yellow as an overlap of the clinical (red) and preclinical (blue) slices.

didactics reportedly translated into significantly increased confidence to function as a resident $(\mathrm{P}=0.03)$ due to the construction of an excellent foundation of knowledge. ${ }^{24}$ However, comparable groups of students requested further case studies and desired more hands-on training. ${ }^{25,26}$

$100 \%$ of lectures, when combined with small group discussion sessions, were found to be effective. Cellerino et al observed that these traditional teaching methods were preferred over more innovative approaches, such as problem-solving case discussions and web-based learning. ${ }^{27}$ These combined sessions significantly improved test averages by $43 \%(\mathrm{P}<0.001)$ and $11 \%(\mathrm{P}<0.05)$ respectively as well as increased basic knowledge of dermatologic cancers. ${ }^{28,29}$ Liu et al did not observe this with more advanced topics such as staging. ${ }^{30}$
This trend continues with holistic care lectures and small group discussions. These sessions reportedly increased $98.7 \%$ of students' self-perceived patient empathy as well as significantly strengthened comfort with conversations of death and dying and delivering bad news. $^{31,32}$ Knowledge gained in these lecture and small group based sessions significantly improved standardized patient interaction, specifically in breast and colon cancer scenarios as well as knowledge of various oncology topics. $^{33-35}$ Berney et al found significantly lower interview scores when individuals participated in small group discussion versus clinical practice $(\mathrm{P}<0.001){ }^{36}$

Fukuchi et al investigated the efficacy of singular small group discussion sections separate from their complementary lectures, showing a significant increase in pre- and post-test performance $(\mathrm{P}=0.018)$ and self-reported general malignancy knowledge. ${ }^{37}$ Students stated that they found their small group sessions to be an effective instructional method and reported an increase self-reported in clinical skills. ${ }^{38}$

The perceived efficacy and reception of lectures to their associated small group discussions was also compared. Kiluk et al found that $57.2 \%$ of the students identified small group discussion as the most helpful part of their experience with $81.2 \%$ reporting a desire for more sessions in the future. ${ }^{31}$ However, Plymale et al reported $80 \%$ satisfaction with lectures compared to $72 \%$ satisfaction with small group discussions. ${ }^{39}$

\section{Clinical Practice and Simulation}

Out of the 35 total papers written about Clinical Practice and Simulation interventions, 97.1\% (34) reported a positive impact while $2.9 \%$ (1) carried mixed results. $54.3 \%$ (19) of these papers analyzed preexisting or experimental methods qualitatively, 34.3\% (12) analyzed their data quantitatively, and $11.4 \%$ (4) used both forms of analysis.

Table 2 Distribution of Intervention Classifications

\begin{tabular}{|l|l|l|l|}
\hline Category of Intervention & Number of Papers & Category of Intervention & Number of Papers \\
\hline Clinical Practice/Simulation & 35 & Blocked vs Integrated Curriculum & 7 \\
\hline Didactic Lecture/Small Group Discussion & 28 & Role Play & 3 \\
\hline Computer-aided Learning & 10 & Multidisciplinary & 4 \\
\hline Early Experience/ Mentorship & 9 & Summer Programs/Electives & 7 \\
\hline Other & 13 & General Review & 27 \\
\hline
\end{tabular}


Although methods of clinical practice and simulation were widely varied, use of standardized patients, anatomical models, and clerkship experience were all associated with significant gain in knowledge. ${ }^{28,40}$ The World Health Organization implemented a clinical practice based curriculum in India with many of these components which received high praise from students. Self-reported increases in knowledge, more positive attitudes towards cancer, and strengthened confidence when dealing with symptomatic treatment of incurable cancer were seen $(\mathrm{P}=0.008){ }^{41,42}$

Clinical practice was preferred to more innovative teaching methods such as problem-based sessions and computer aided learning, with students showing significantly higher interview and clinical skills scores using the former. ${ }^{25,27,34,36}$ Kissane et al reported a similar relationship with lectures and pre-planned classroom time as well. ${ }^{26}$ Structured clinical experience was also rated more highly $(92 \%)$ than both lectures $(80 \%)$ and small group discussions (72\%) on similar topics. ${ }^{39}$ Skye et al observed that the use of standardized patients, especially in the setting of giving bad news, helped to "enhance realism" and "push students outside of their comfort zones.",43

Additional studies explored the use of cancer survivors in place of standardized patients when providing this practical experience to students. Medical students rated the benefit of using cancer survivors "highly" with the patients reporting strong willingness to participate in future courses. ${ }^{44}$ Increased confidence with breaking bad news and use of the patient's preferred communication techniques were also seen, along with increased emotional impact due to firsthand experience with the topic at hand. ${ }^{45}$

Clinical practice in medical school significantly correlated with self-reported preparedness to care for patients with cancer (OR 1.48; 95\% CI 1.22-1.79) as well as further "confidence and control" over interactions with dying patients and end of life care. ${ }^{46,47}$ Abrão et al and Fresier et al indicated a significant correlation between ability to practice skills, perceived knowledge, and counseling/screening skills. This was especially true in studentled outpatient clinics, with individuals reporting improved clinical skills, long term knowledge retention, and improved interest in pursuing oncology. ${ }^{48,49}$ No compromise in patient care was reported in these cases. ${ }^{50}$ This was not seen with simple observation of similar experiences or with non-repetitive and short term practice. ${ }^{51-54}$ Significant improvement in self-perceived palliative care ability $(\mathrm{P}<0.001)$ and the psychosocial impact of cancer on patients was observed as well. ${ }^{13,35}$

Multi-part simulations helped students in a similar fashion, with significant improvement seen in survivorship care $(\mathrm{P}=0.002)$ and comfort when discussing effects of cancer treatments $(\mathrm{P}=0.001) .{ }^{33}$ This was seen in both de novo simulations and those added to pre-existing curricula. ${ }^{55}$ Formative assessment of these same skills also showed significant pre- and post-test improvement $(\mathrm{P}<0.0001){ }^{13}$

Similarly structured communication skills workshops showed positive improvements in self-reported patient care and comfort abilities in pre- and post-experience surveys. ${ }^{56}$ Mandatory, integrated sessions also provided higher levels of comfort with patient and family communication, efficacy of delivery of care, and total value of care $(\mathrm{P}=0.026,0.001$, 0.011). Participants rated this experience as their favorite part of medical school followed closely by clinical rotations. ${ }^{57}$ Uijtdehaage et al reported that some students were frequently exposed to cancer survivors in medical school but only received partial opportunities to practice critical components of survivorship care. ${ }^{58}$

Uniquely, portfolio construction of experienced patient interactions significantly improved formative assessment $(\mathrm{P}=0.04)$ and OSCE results $(\mathrm{P}=0.01)$ but found no significant difference in measured clinical competence. ${ }^{59}$ Additionally, combining clinical practice with small group discussions appeared beneficial to students as "an effective instructional method" and way to increase clinical skills. ${ }^{19}$ This same relationship appeared to be supported with analysis and discussion of video-taped standardized patient interactions. $98.3 \%$ of students reported the experience to be helpful and $81.2 \%$ of students requested more sessions in the future. ${ }^{31}$

Use of various static and dynamic breast models reportedly increased student accuracy in detecting various masses and improved clinical true positive scores $(\mathrm{P}<$ 0.05). ${ }^{40,60,61}$ Results are not limited to breast models, with self-reported improvement of testicular cancer detection after practice on anatomical models as well. ${ }^{15}$

\section{Summer Programs and Electives}

Out of the seven papers written about Summer Programs and Electives, $100 \%$ (7) reported a positive impact on oncology education. $28.6 \%$ (2) of these papers analyzed preexisting or experimental methods relating to teaching oncology qualitatively and $71.4 \%$ (5) analyzed their data quantitatively, while zero used both forms of analysis. 
$100 \%$ of quantitative papers analyzed showed a statistically significant increase in pre- and post-test scores in all areas assessed. Lutgendorf-Caucig et al found an increase in student knowledge in both general and specific aspects of cancer $(\mathrm{P}=0.005, \mathrm{P}<0.001) .{ }^{62}$ Statistically significant increases attendees' test results $(\mathrm{P}=0.001)$, student clinical and research oncology understanding ( $\mathrm{P}<0.01, \mathrm{P}<0.01)$, and comfort in daily oncology care $(P=0.001)$ were also observed in various other cancer-focused summer programs. ${ }^{63-65}$ Students who participated in optional radiation oncology clinical rotations scored significantly higher overall on acquired knowledge. $^{66}$

The two qualitative studies examined the affective aspect of these summer programs. Pavlidis et al showed that students reported their experience at a five day course to be very useful in improving both cancer knowledge and clinical skills. ${ }^{5}$ Fromm-Haidenberger reported high satisfaction with both content and range of their program as well and concluded that this strategy was a useful tool to teach oncology to medical students. ${ }^{67}$

\section{Computer Aided Learning}

Out of the 10 papers written about using Computer Aided Learning to teach oncology, $50 \%$ (5) of these papers reported a positive impact while $50 \%$ (5) found the intervention to have a mixed or negative impact.

Positive impact studies showed an increase in both academic understanding and clinical performance. Morgulis et al showed that students who had access to e-module resources performed slightly better than those who did not. ${ }^{68}$ Fukuchi et al also found that their online game increased understanding and knowledge of malignancies. ${ }^{37}$ Additionally, students who used interactive computer video tutorials rated the experience as more helpful than learning from a textbook and reported increased communications skills. ${ }^{69,70}$ Uijtdehaage et al created a variety of digital oncology modules which were received well by students, however no analysis regarding specific content was completed. ${ }^{28}$

In some cases the use of computer programs did not improve students' understanding versus more traditional teaching methods. Gaffen et al used standardized patients, breast models, and computer programs to assist in breast cancer screening lessons and stated that the computer program did not improve students' learning more than the other methods. ${ }^{40}$ Students who were exposed to both traditional classroom and computer aided learning showed no significant difference in formative assessments compared to those exposed only to traditional teaching. However, $75 \%$ of students surveyed mentioned that they viewed the web-based materials as an important resource. $^{71}$

Międzybrodzka et al and Markova et al both experimented with changing various curricular components from in-person to web-based learning. Neither saw any significant changes in either understanding or patient care outcomes. ${ }^{72,73}$ Mayer et al observed institution-wide implementation of computer-aided learning tools which resulted in variable uptake and qualms regarding its inability to teach certain, difficult topics. ${ }^{74}$

\section{Early Experience and Mentorship}

Out of the nine papers written about Early Experience and Mentorship being used to teach oncology, $100 \%$ (9) reported positive results. $55.6 \%$ (5) analyzed data qualitatively while $44.4 \%$ (4) analyzed data quantitatively.

The quantitative studies collectively support the use of mentorship programs to help students better understand oncology related material while giving them insight and early experience into the field of clinical oncology. Barrett et al reported that students who had mentors in either clinical or research oncology were 5.76 times more likely to match into oncology than other students. ${ }^{75}$ Hirsch et al found that $29.3 \%$ of medical students who were mentored by faculty radiation oncologists applied and matched into radiation oncology residencies. ${ }^{76}$ De la Peña \& GarciaLinares found significant improvement in post-test study scores after Radiation Oncologist teaching and mentorship during third year rotations $(\mathrm{P}<0.005)$ with similar results observed after exposure to oncology rotations in general. ${ }^{21,77}$ Additionally, second year students given a one week introductory clinical oncology course were taught to be more comfortable about death $(\mathrm{P}<0.001)$ and encouraged early decisions about oncology residency $(\mathrm{P}=0.013){ }^{32}$

Qualitative studies were very positive as well. Tarkowski et al outlined a student scientific society where members were encouraged to explore oncology in a variety of extracurricular activities, resulting in increased self-reported interest in cancer treatment. ${ }^{78}$ Agarwal et al looked at different experiences students could participate in prior to matching, with special consideration to studentrun cancer societies. These experiences were found to foster early interest in oncology and had the potential to create more successful radiation oncology applicants. 
However, a lack of easily accessible mentorship in this field was noted with calls to increase student-mentor connections. ${ }^{79,80}$ DeNunzio et al found mentorship to be a "cornerstone to strengthening the radiation oncology educational experience." Additionally, this study found multiple mentors to be helpful, especially when distributed across the academic spectrum and not too far removed from their own medical school education. ${ }^{81}$

\section{Integrated Didactics versus Blocked}

\section{Curriculum}

Out of the seven papers written about Integrated Didactics versus Blocked Curricula being used to teach oncology, $85.7 \%$ (6) reported positive results with one study reporting variable results. $28.6 \%$ (2) were qualitative and $71.4 \%$

(5) were quantitative.

Blocked oncology clerkships led to students feeling reassured about their career decisions compared to their undecided peers. $^{82}$ Jefferson Medical College offered a three week clinical rotation with post-surveys collected one and a half years later. $64 \%$ of students stated that they planned on seeing oncologic patients in their career and the rotation helped fill gaps in knowledge of end-of-life management, empathy, and evidence-based medicine. ${ }^{83}$ Pre- and post-examination of students at Freeman Hospital after two-week clinical placements found that significantly more students considered applying into oncology $(\mathrm{P}=0.013)$. Associated improvements in ability to break bad news, recognize red flags, and awareness regarding difficulties of cancer management were also observed. ${ }^{84}$

Students who received oncology education in medical school, or had earlier exposure to patients with cancer, said that they felt more prepared to speak with cancer patients. A survey of UK medical students found that 61\% (95\% CI 59-63\%) wanted more early oncology teaching and exposure, especially in radiotherapy and chemotherapy. ${ }^{46}$

Geller el al showed an increase in the number of hours spent on cancer education from six (1996) to 15 (1999). Within three years, tobacco cessation counseling skills increased significantly $(\mathrm{P}<0.001)$ and fourth year students reported less worry regarding cancer prevention care $(\mathrm{P}<0.001) .{ }^{85}$ At this same institution, Hirsch et al established an Oncology Education Initiative and integrated structured didactics into a radiology clerkship, resulting in an $11 \%$ pre- and post-test improvement $(\mathrm{P}=0.011)^{22}$

Fernandes et al tested the difference between teaching oncology in a concentrated semester versus in multiple courses over the span of three years. Initially, the group with the spaced-out curriculum scored higher and had faster growth in knowledge. However, the acceleration of learning slowed down for these students, and on the final exam the students with the blocked curriculum performed better. $^{86}$

\section{Role Play}

Out of the three papers written about Role Play being used to teach oncology, $100 \%$ (3) reported positive results. $100 \%$ of these papers were qualitative in nature.

The two qualitative publications emphasized the lack of focus on patient-centered care. Mann et al noted that having a more multidisciplinary approach to cancer treatment stimulated discussion and focused more on the psychological perspective of medicine. ${ }^{87}$ Medical students who practiced role play with one another in a clinical setting reported satisfaction with the experience. One student remarked that the last student in particular approached their diagnosis of testicular cancer expertly, with no belittlement or exaggeration of risk. ${ }^{88}$ Skye et al used an interactive theater workshop and found that $94 \%$ of students stated the exercise stimulated reflection about "patient-provider communication" and 89\% stated that the workshop provoked discussion. ${ }^{43}$

\section{Multidisciplinary Teams}

Out of the four total papers found written about the efficacy of Early Experience and Mentorship being used to teach oncology, $100 \%$ (4) of these papers reported positive results and were quantitative in nature.

Fukuchi et al showed an increase in student knowledge after playing a computer assisted board game which aimed to teach a multidisciplinary approach to cancer treatment. $^{37}$ Students also showed an increase in selfreported oncology knowledge after taking part in a summer oncology multidisciplinary research experience $(\mathrm{P}<0.01) .{ }^{64}$ Head et al focused on the implementation of interdisciplinary palliative care in a medical school curriculum for medical students. Results showed that, after the program was administered, there was a significant increase in oncology knowledge in pre- and post-test results. ${ }^{57}$ Similarly, Lutgendorf-Caucig et al showed that the use of a summer program employing a multidisciplinary teaching 
approach increased knowledge in both general and specific aspects of cancer $(\mathrm{P}=0.005$ and $\mathrm{P}<0.001) .{ }^{62}$

\section{Other}

13 interventions were found to not fit into at least one of the categories listed above.

Use of a portfolio of patient interactions, coupled with clinical practice, showed no significant difference in annual clinical competence. However, students had significantly better quantitative OSCE results $(\mathrm{P}=0.01)$ and formative assessment results $(\mathrm{P}=0.04) .{ }^{59}$

An interactive contouring module aimed towards second year students to teach the fundamentals of radiation therapy showed no significant difference in overall demonstrated knowledge versus traditional lecture based learning $(\mathrm{P}=$ 0.10). Significant differences were found in knowledge of radiation therapy and side effects $(\mathrm{P}=0.002)$ along with greater reported engagement $(\mathrm{P}=0.02)$ and interest in pursuing a clinical radiation oncology rotation $(\mathrm{P}=0.01) .{ }^{89}$

Belfrage et al investigated the use of humor and observed that $94 \%$ of students viewed humor as an effective way to create a relaxed learning environment and make learning more enjoyable. Humor was best received when incorporated approximately three times per 45 minute session. $70 \%$ of students noted that it was most effectively used when coupled with interesting clinical cases. ${ }^{90}$

Skye et al explored the use of interactive theater to practice giving bad news found that $94 \%$ of students reported increased self-reflection on patient-provider communication. $87 \%$ reported increased peer-to-peer discussion of complex issues surrounding breaking bad news. Use of professional actors during the exercises enhanced realism and more closely approximating real life clinical situations. ${ }^{43}$

The use of a brief, learner-centered, breaking bad news communication skills training module found significantly increased breaking bad news scores and patient interaction in both colon $(\mathrm{P}=0.007)$ and breast $(\mathrm{P}=0.003)$ cancer scenarios. $^{33}$

Surveys regarding integration of religion and spirituality into medical school training found support for a longitudinal, elective, and experiential curriculum which would occur alongside the general pre-existing curriculum. Those questioned agreed that it should focus on the impact of integration of religious and spiritual values and self-care practices with care for patients and interactions with the medical team. ${ }^{91}$

A flipped classroom curriculum for teaching gynecologic oncology topics found that, although only $80 \%$ of students completed preassigned educational work, the attendance rate was $94 \%$ with "very high" reported student satisfaction. No significant difference in aggregate student performance on the oncology questions of the Obstetrics and Gynecology NBME Subject Examination was found. ${ }^{92}$

Turner et al surveyed radiation oncology professionals to identify what leadership skills, behaviors, and knowledge could be taught in medical school in order to develop the next-generation of leaders in the field. ${ }^{93}$

A multi-national study which evaluated competitive spaced repetition (Cancer Cup Challenge) reported that $82.3 \%$ of students found the competition to be an enjoyable experience. $82 \%$ of students found the cases to be relevant while $76.5 \%$ found them interesting. Reception of the computer nature of this intervention was positive. ${ }^{94}$

De Visser et al looked at the effectiveness in creation of posters on the topic of adjuvant endocrine breast cancer for patient education versus answering case-based questions in small groups. No difference in knowledge was observed through the use of formative multiple-choice questions. Questionnaires filled out by the students showed that those in the case-based question group had higher perceived participation and satisfaction $(\mathrm{P}<0.05) .^{95}$

A traditional curriculum of several hourly educational sessions per week versus a half-day educational format during Hematology/Oncology clinical blocks found that half day sessions were preferred. Students reported increased motivation to attend, concentration, and knowledge retention along with increased exam scores. ${ }^{96}$

A narrative writing course regarding experience with cancer patients reported that $84 \%$ found the experience useful. Surveys showed that the key strength of the course was openness of discussion of issues typically not part of a traditional oncology curriculum and the main weakness to be lack of additional faculty member involvement in these discussions. ${ }^{13}$

A redesigned, combined oncology and surgical clerkship with a focus on longitudinal, long term follow-up of gastrointestinal cancer and breast cancer patients was explored at Harvard Medical School. Students reported that their experience, on average across seven months, "facilitated their understanding of cancer in a way not feasible in a traditional clerkship model" with improvement in integrated learning of surgical, medical, and social issues. ${ }^{97}$

\section{General Review}

A total of 27 papers were found evaluating or reviewing the current state of oncology education. 51.9\% (14) of 
these papers originated from or reviewed the United States while the other $48.1 \%$ (13) reviewed various countries in Europe, Asia, Africa, and Oceania.

An international study revealed that many countries throughout Europe and Asia have varying degrees of recognition of oncology as a specialty, including the various subspecialties such as medical and radiation oncology. Although countries such as the Netherlands and Turkey describe medical oncology as its own distinct specialty, other Baltic countries often combine it with radiation oncology. Russia, Belarus, and Ukraine have varying degrees of recognition of oncology as a specialty, with the most specific simply terming it "General Oncology." Additionally, European guidelines for a standardized oncology curriculum appear to be widely variable with respect to adoption. Various countries have adopted unique pieces of the curriculum with some regions adjusting it to fit local circumstances. ${ }^{98}$

Oncology education in the United States shows wide variability in a number of areas. Mattes et al revealed that less than 10 total hours in the first/third years and less than 20 total hours in the second year of medical school were dedicated to cancer instruction. Exposure to radiation oncologists was also low until the beginning of third year clerkships. Oncology related didactics only comprised three to four hours combined didactic hours between four to six month Internal Medicine and Surgical clerkships. ${ }^{11}$ A lack of Oncologists in educator positions and infrequent requirements for students to rotate through non-surgical oncology clerkships have also been reported. ${ }^{10}$ Most often oncology has been combined with radiology clerkships through didactic sessions focused on tumor biology and treatment, with less than $1 / 3$ of all schools having a dedicated curricula. ${ }^{99,100}$

Current education focuses more on traditional methods of teaching such as lectures and small group discussions. ${ }^{101}$ However, research in the United States has proposed optimal preclinical oncology curricula with an emphasis on medical knowledge and patient communication with acknowledgement of pitfalls. ${ }^{4}$ Implementation has reported high interest in learning oncology in an interdisciplinary manner. ${ }^{102}$ Nonstandard methods, including replacement of hourly didactic sessions with focused half-day blocks and a focus on palliative care and radiation oncology have been implemented as well. ${ }^{103-106}$ Although achieved, surveys show a lack of knowledge among students, with some still reporting misconceptions about various oncologic topics and a lack of preparation for survivorship care. ${ }^{58,107}$

Issues are not limited to the United States. Cheung et al found that, in Canadian medical schools, cancer constitutes less than $10 \%$ of the curriculum and less than $10 \%$ of the final exam in $70.6 \%$ and $58.8 \%$ of institutions respectively. ${ }^{108}$ Similar statistics are true in Australia and New Zealand as well, with 94\% reporting no formal oncology curriculum and $44 \%$ indicating no intention of changing in the future. ${ }^{109}$ Additionally, $78 \%$ of Australian medical students reported dissatisfaction with the number of dedicated oncology teaching hours. ${ }^{110}$ However, efforts have been made to implement some standardized curricula, with preliminary results indicating adequate direction to acquire necessary competencies, stimulus for learning opportunities, and positive contributions to participant development. ${ }^{75}$

Reviews of European medical schools show similar results. Polish curricula lack standardized exams to assess oncology training, educational facilities, oncological gynecologists, and palliative medicine courses. ${ }^{111}$ Swiss schools were also found to not have standardized palliative medicine courses in addition to a wide variation in required number of hours, topics, and teaching methods for oncology. ${ }^{112}$ Lithuanian medical education was also lacking in undergraduate schools with little to no standardization on a national scale. ${ }^{113}$

Norway's curricula, which focused on physician empathy, had the highest reported feelings of satisfaction. ${ }^{89}$ Additionally, use of a blocked rather than integrated curriculum significantly improves test scores at the national level. ${ }^{114}$ A Finnish study indicated wide variation in palliative care oncology training, teamwork, and selfreflection while reportedly being strong in basic knowledge, symptom management, and communication skills practice. This study also showed that compliance with European guidelines resulted in increased test scores. ${ }^{115}$

Further reviews indicate issues in Asia and Africa as well. Only $43.9 \%$ of Japanese medical schools have compulsory palliative care sessions, while $30.3 \%$ have no clinical clerkship curriculum at all. ${ }^{116}$ Teaching in Thailand revealed a lack of coping management skills when caring for palliative care patients while at least one school in India has no cancer education program at all. ${ }^{117}$ Egyptian medical education showed a national public health based approach to cancer education which even requires completion of a community service project, however it lacks standardized training in cancer education and prevention. Data showed a lack of a dedicated oncology curriculum and interaction with cancer patients at all medical schools in the country except Cairo University. ${ }^{118}$ 


\section{Discussion}

General Review papers showed both domestic and international variability in oncology curricula regarding specific specialties and topics represented, total number of hours taught, and integrated versus blocked presentations. A greater number of hours spent learning appeared to correlate with higher retention of material and greater exposure to specialties within oncology, including radiation oncology and palliative care. In addition, although standardized curricula have been proposed in multiple regions, adoption appears to be varied, even when provided with the tools to overcome commonly faced obstacles. There is also the issue of a lack of recognition of oncology and its various subspecialties in multiple countries, leading to "cancer education deserts."

Out of the interventions analyzed, Clinical Simulation and Practice, Role Play, Summer/Elective Programs and interventions involving Multidisciplinary Team Work all appeared to be "Highly Effective" in teaching oncology to medical students.

In nearly all scenarios in which students were formally evaluated, Clinical Simulation and Practice showed statistically significant improvement between pre-test and posttest understanding. Due to the reported high satisfaction seen in post-experiential surveys and desire for further sessions, this intervention appears well supported to dramatically increase students' clinical and practice skills in an engaging and welcoming environment.

Although limited by its small sample size, Role Play could be coupled with this intervention as well. Whether it be learning how to deliver bad news, speaking to patients about their symptoms, or any variety of challenging scenarios, Role Play gives students a chance to practice difficult situations before entering the wards.

Summer and Elective Programs as a whole gave motivated students an opportunity to further their growth of knowledge and clinical skills in the area of oncology. Reportedly high student satisfaction, along with statistically significant increases in all formative assessments given, make these intra- and extracurricular activities a valuable tool. Additionally, they can be implemented outside of the curriculum to give students extra opportunities to explore the field. Coupling this with Multidisciplinary Teamwork would allow students to explore a whole new dimension of oncology that is not immediately evident on the surface. This would allow for further exploration of the multi-faceted nature of oncology while also effectively learning the topics at hand.
Intensive Block Programs, Didactic Lectures/Small Group Discussions, and Computer and Web Based Education tools were only "Moderately Effective."

Through various avenues medical schools have implemented both integrated and blocked curricula in order to better prepare students to handle cancer patients. Although both types of curricula appear to be nearly identical in their effectivity, the variability and difficulty in their implementation lies with the medical students. Students appeared split on their desire for a blocked, focused approach to oncology versus an integrated one. In some cases, students preferred the opposite curriculum to what was currently implemented at their institution. A possible solution would be to implement a balanced system, with an integrated curriculum throughout the "Preclinical" years and a blocked curriculum via rotations and didactics during the "Clinical" years.

Didactic Lectures and Small Group Discussions are one of the most traditional teaching methods used in medical schools. Although they are effective at conveying information and lead to significant increases in performance on formative assessments, various studies still indicate student desire for more interactive educational experiences. Even the addition of complementary small group case discussions fail to satisfy when it comes to interactions better suited for clinical simulation/ practice. There also continues to be a lack of comprehensive oncology teaching by specialty-specific physicians associated with the topic at hand. The desire to fill this gap is expressed by many medical students and research indicates that proper staffing leads to significantly increased test scores as a result.

Computer and Web Based Education, although highly rated on post-interventional surveys, showed variable pretest and post-test results between experimental and control groups. An unexpected result from this intervention group was the increased use of "in-person help" which was observed to be highly valued and student driven regarding the material presented online. Additionally, the time intensive task of creating a computer program may not be worth the time if the general trend states that new technology does not necessarily improve understanding of medical concepts. That being said, our results were based on a limited number of studies. We should be cautious about the uptake of new technology and further explore the role of teachers as facilitators in the realm of online learning.

"Other" interventions supported the use of humor throughout the curriculum, competition based learning, theater-based practice of clinical and patient skills, a narrative writing course regarding patient experiences with their diagnoses and treatment, and portfolio creation 
of a longitudinal patient experience. Although these were all deemed to have a positive outcome over various measured metrics, our sample size is incredibly small, both within many of the studies as well as of the type of intervention themselves. If implementation were desired, a balance should be made between the need to have the specific teaching method in the program and the magnitude of effort required to incorporate it into the curriculum.

Our study was limited by several key factors. The first was the small number of electronic databases that we used: PubMed, MEDLINE, Embase, and MedEdPORTAL. Because we did not expand our search outside of these sources our results were limited by the studies cataloged in these databases. Searching in larger publication pools, such as Google Scholar, may have yielded further studies which could have been included in our analysis. This also may contribute to the second identified limitation, which is the paucity of studies outside of North America, Europe, or other high income countries. Because of the main focus on the aforementioned areas, we would have a hard time accurately characterizing the global state of oncology education. This could have also led to the small sample sizes of both the Role Play and Multidisciplinary Team interventions, affecting our final conclusions. The third limitation we identified was our analysis of the qualitative studies in this paper. Although judgement of their results were analyzed collectively by the authors of this paper, the wide variety of formats and interventions may have made it difficult to remain completely objective. Additionally, due to the lengthy nature of our thorough analysis, database searches were not conducted after January 2019. Although new research may have been published during the writing process, we believe that our findings are still highly applicable and will prove useful to future researchers and medical school instructors.

\section{Conclusion}

Overall, the interventions that had the most positive impact on student learning and performance were Clinical Simulation and Practice, Role Play, Summer/ Elective Programs, and Multi-Disciplinary Teamwork. These programs should be highly considered in the future creation of oncology curricula. The use of Intensive Block Programs, Didactic Lectures/Small Group Discussions and Computer/Web Based Education were all variable in efficacy and should be implemented with caution.

These findings may help propose a theoretical, standardized oncology curriculum for medical schools to implement not only in the United States but internationally as well. This can be further realized through more comprehensive and unbiased studies looking into global oncology curricula in order to analyze if there exists a place for such a program to thrive. We hope that the information we gathered and analyzed will help prepare current and future medical students to tackle the rapidly growing need of cancer care and treatment worldwide.

Further studies could also explore the division and efficacy of different teaching strategies at the graduate versus postgraduate levels. The variety of residency and fellowship programs worldwide would provide a stark contrast to that of the medical school classroom, with different interventions working in unique settings. Analyses could also be done with a focus on oncology education within specific continents in order to remove various forms of selection biases.

\section{Acknowledgments}

This research was partially funded by The Medical Student Summer Research Program, Boston University School of Medicine.

\section{Disclosure}

Andrew Klufas reports a grant from the Medical Student Summer Research Program at Boston University School of Medicine during the conduct of the study. The authors report no other potential conflicts of interest for this work.

\section{References}

1. Naghavi M, Abajobir AA, Abbafati C, et al. Global, regional, and national age-sex specific mortality for 264 causes of death, 1980-2016: a systematic analysis for the Global Burden of Disease Study 2016. The Lancet. 2017;390(10100):1151-1210. doi:10.1016/ S0140-6736(17)32152-9

2. Ferlay J, Colombet M, Soerjomataram I, et al. Estimating the global cancer incidence and mortality in 2018: GLOBOCAN sources and methods. Int J Cancer. 2019;144(8):1941-1953. doi:10.1002/ijc.31937

3. American Cancer Society. Cancer Facts and Figures: the Global Cancer Burden; 2019. https://www.cancer.org/content/dam/cancer-org /research/cancer-facts-and-statistics/annual-cancer-facts-and-figures /2019/cancer-facts-and-figures-2019.pdf.

4. DeNunzio NJ, Joseph L, Handal R, Agarwal A, Ahuja D, Hirsch AE. Devising the Optimal Preclinical Oncology Curriculum for Undergraduate Medical Students in the United States. $J$ Cancer Educ. 2013;28(2):228-236. doi:10.1007/s13187-012-0442-0

5. Pavlidis N, Vermorken JB, Stahel R, et al. Undergraduate training in oncology: an ESO continuing challenge for medical students. Surg Oncol. 2012;21(1):15-21. doi:10.1016/j.suronc.2010.07.003

6. Oncology Education Committee of Australia. Ideal oncology Curriculum for Medical Schools; 2007. Available from: https://www. cancer.org.au/content/pdf/HealthProfessionals/OncologyEducation/ IdealOncologyCurricDEC07-updatedcover.pdf. 
7. Granek L, Mizrakli Y, Ariad S, Jotkowitz A, Geffen DB. Impact of a 3-Day Introductory Oncology Course on First-Year International Medical Students. J Cancer Educ. 2017;32 (3):640-646. doi:10.1007/s13187-015-0972-3

8. Al Suwayri SM. Feasibility and Outcomes of Oncology Teaching for 5th Year Medical Students. J Cancer Educ. 2018;33(1):83-88. doi:10.1007/s13187-016-1031-4

9. Agarwal A, Koottappillil B, Shah B, Ahuja D, Hirsch AE. Medical Student-Reported Outcomes of a Radiation Oncologist-Led Preclinical Course in Oncology: A Five-Year Analysis. Int J Radiat Oncol. 2015;92(4):735-739. doi:10.1016/j.jijrobp.2015.03.008

10. Neeley BC, Golden DW, Brower JV, Braunstein SE, Hirsch AE, Mattes MD. Student Perspectives on Oncology Curricula at United States Medical Schools. J Cancer Educ. 2019;34 (1):56-58. doi:10.1007/s13187-017-1265-9

11. Mattes MD, Patel KR, Burt LM, Hirsch AE. A Nationwide Medical Student Assessment of Oncology Education. $J$ Cancer Educ. 2016;31(4):679-686. doi:10.1007/s13187-015-0872-6

12. Shapiro CL, Jacobsen PB, Henderson T, et al. ReCAP: ASCO Core Curriculum for Cancer Survivorship Education. $J$ Oncol Pract. 2016;12(2):145. doi:10.1200/JOP.2015.009449

13. Dignan M, McQuellon R, Michielutte R, Brewer C, Atwell B, Cruz J. Helping students respond to stressful interactions with cancer patients and their families: a pilot program. $J$ Cancer Educ. 1989;4(3):179-183. doi:10.1080/08858198909528000

14. Madan AK, Colbert PM, Beech B, Beech DJ. Effect of a Short Structured Session on Medical Student Breast Cancer Screening Knowledge. Breast J. 2003;9(4):295-297. doi:10.1046/j.15244741.2003.09408.x

15. Taylor JS, Dube CE, Pipas CF, Fuller BK, Lavallee LK, Rosen R. Teaching the testicular exam: a model curriculum from "A" to "Zack.". Fam Med. 2004;36(3):209-213.

16. Hwang L. Cancer Awareness Changes After an Educational Intervention Among Undergraduate Students; 2013. Accessed January 30, 2019. https://link.springer.com/article/10.1007\% 2Fs13187-013-0461-5.

17. Coutinho F, Ramessur A. An Overview of Teaching Communication of Bad News in Medical School: should a Lecture be Adequate to Address the Topic? Acta Médica Portuguesa. 2016;29(12):826-831. doi:10.20344/amp.7909

18. Klafke N, Homberg A, Glassen K, Mahler C. Addressing holistic healthcare needs of oncology patients: implementation and evaluation of a complementary and alternative medicine (CAM) course within an elective module designed for healthcare professionals. Complement Ther Med. 2016;29:190-195. doi:10.1016/j.ctim.2016.10.011

19. Hirsch AE, Handal R, Daniels J, et al. Quantitatively and Qualitatively Augmenting Medical Student Knowledge of Oncology and Radiation Oncology: an Update on the Impact of the Oncology Education Initiative. J Am Coll Radiol. 2012;9 (2):115-120. doi:10.1016/j.jacr.2011.07.001

20. Agarwal A, Shah A, Shah B, Koottappillil B, Hirsch AE. The Impact of a Radiation Oncologist led Oncology Curriculum on Medical Student Knowledge. $J$ Cancer Educ. 2018;33 (6):1176-1180. doi:10.1007/s13187-017-1227-2

21. De la Peña L, Garcia-Linares A. Radiotherapy Learning in Medical Undergraduate Courses. J Cancer Educ. 2016;31 (4):660-665. doi:10.1007/s13187-015-0868-2

22. Hirsch AE, Mulleady Bishop P, Dad L, Singh D, Slanetz PJ. An Increase in Medical Student Knowledge of Radiation Oncology: A Pre-Post Examination Analysis of the Oncology Education Initiative. Int J Radiat Oncol. 2009;73(4):1003-1008.e2. doi:10. 1016/j.ijrobp.2008.12.012

23. Hirsch AE, Singh D, Ozonoff A, Slanetz PJ. Educating Medical Students About Radiation Oncology: initial Results of the Oncology Education Initiative. J Am Coll Radiol. 2007;4 (10):711-715. doi:10.1016/j.jacr.2007.06.011
24. Jagadeesan VS, Raleigh DR, Koshy M, Howard AR, Chmura SJ, Golden DW. A National Radiation Oncology Medical Student Clerkship Survey: didactic Curricular Components Increase Confidence in Clinical Competency. Int $J$ Radiat Oncol. 2014;88(1):51-56. doi:10.1016/j.ijrobp.2013.11.206

25. Ye JC, Mohindra P, Spektor A, et al. Medical Student Perspectives on a Multi-institutional Clerkship Curriculum: A Report From the Radiation Oncology Education Collaborative Study Group. Int $J$ Radiat Oncol. 2015;92(2):217-219. doi:10.1016/j.ijrobp.2015.01.043

26. Kissane DW, Bylund CL, Banerjee SC, et al. Communication Skills Training for Oncology Professionals. J Clin Oncol. 2012;30(11):1242-1247. doi:10.1200/JCO.2011.39.6184

27. Cellerino R, Graziano F, Piga A, Ghetti V. The teaching of clinical oncology in Italian medical schools. A survey among teachers and students. Ann Oncol. 1993;4(9):717-721. doi:10.1093/oxfordjournals.annonc.a058654

28. Uijtdehaage S, Hauer KE, Stuber M, Rajagopalan S, Go VL, Wilkerson LA. Framework for Developing, Implementing, and Evaluating a Cancer Survivorship Curriculum for Medical Students. J Gen Intern Med. 2009;24(Suppl 2):491-494. doi:10.1007/s11606-009-1024-7

29. Golden DW, Kauffmann GE, McKillip RP, et al. Objective Evaluation of a Didactic Curriculum for the Radiation Oncology Medical Student Clerkship. Int J Radiat Oncol. 2018;101 (5):1039-1045. doi:10.1016/j.ijrobp.2018.04.052

30. Liu K, Barankin B, Howard J, Guenther L. One-Year Followup on the Impact of a Sun Awareness Curriculum on Medical Students' Knowledge, Attitudes, and Behavior. J Cutan Med Surg. 2001;5(3):193-200. doi:10.1177/120347540100500301

31. Kiluk JV, Dessureault S, Quinn G. Teaching Medical Students How to Break Bad News with Standardized Patients. J Cancer Educ. 2012;27(2):277-280. doi:10.1007/s13187-012-0312-9

32. Granek L, Lazarev I, Birenstock-Cohen S, Geffen DB, Riesenberg K, Ariad S. Early Exposure to a Clinical Oncology Course During the Preclinical Second Year of Medical School. Acad Med. 2015;90(4):454-457. doi:10.1097/ACM.000000000 0000521

33. Gorniewicz J, Floyd M, Krishnan K, Bishop TW, Tudiver F, Lang F. Breaking Bad News to Patients with Cancer: A Randomized Control Trial of a Brief Communication Skills Training Module Incorporating the Stories and Preferences of Actual Patients. Patient Educ Couns. 2017;100(4):655-666. doi:10.1016/j.pec.2016.11.008

34. Golden DW, Spektor A, Rudra S, et al. Radiation Oncology Medical Student Clerkship: implementation and Evaluation of a Bi-institutional Pilot Curriculum. Int J Radiat Oncol. 2014;88 (1):45-50. doi:10.1016/j.ijrobp.2013.10.041

35. Renton K, Quinton H, Mayer A-PT. Educational impact of paediatric palliative simulation study days. BMJ Support Palliat Care. 2017;7(1):88-93. doi:10.1136/bmjspcare-2015-000883

36. Berney A, Carrard V, Mast MS, Bonvin R, Stiefel F, Bourquin C. Individual training at the undergraduate level to promote competence in breaking bad news in oncology. Psychooncology. 2017;26(12):2232-2237. doi:10.1002/pon.4452

37. Fukuchi SG, Offutt LA, Sacks J, Mann BD. Teaching a multidisciplinary approach to cancer treatment during surgical clerkship via an interactive board game. Am J Surg. 2000;179 (4):337-340. doi:10.1016/S0002-9610(00)00339-1

38. Sloan DA, Donnelly MB, Plymale M, McGrath PC, Kenady DE, Schwartz RW. The structured clinical instruction module as a tool for improving students' understanding of breast cancer. Am Surg. 1997;63(3):255-260.

39. Plymale M, Donnelly MB, Blue AV, et al. A multidimensional approach to breast cancer education. J Cancer Educ. 2000;15 (1):5-9. doi:10.1080/08858190009528644 
40. Gaffan J, Dacre J, Jones A. Educating Undergraduate Medical Students About Oncology: A Literature Review. J Clin Oncol. 2006;24(12):1932-1939. doi:10.1200/JCO.2005.02.6617

41. Kapoor N, Haagedoorn EML, de Vries J. The UICC/WHO-CCCE cancer education project: an Indian experience. J Cancer Educ. 2006;21(3):182-185. doi:10.1207/s15430154jce2103 19

42. Starmer D, Jamrozik K, Barton M, Miles S. Evaluating curriculum changes in undergraduate cancer education. J Cancer Educ. 2004;19(3):156-160. doi:10.1207/s15430154jce1903_9

43. Skye EP, Wagenschutz H, Steiger JA, Kumagai AK. Use of Interactive Theater and Role Play to Develop Medical Students' Skills in Breaking Bad News. J Cancer Educ. 2014;29 (4):704-708. doi:10.1007/s13187-014-0641-y

44. Plymale MA, Witzke DB, Sloan PA, Blue AV, Sloan DA. Cancer survivors as standardized patients: an innovative program integrating cancer survivors into structured clinical teaching. J Cancer Educ. 1999;14(2):67-71. doi:10.1080/08858199909528 582

45. Baer AN, Freer JP, Milling DA, Potter WR, Ruchlin H, Zinnerstrom KH. Breaking bad news: use of cancer survivors in role-playing exercises. J Palliat Med. 2008;11(6):885-892. doi:10.1089/jpm.2007.0253

46. Cave J, Woolf K, Dacre J, Potts HWW, Jones A. Medical student teaching in the UK: how well are newly qualified doctors prepared for their role caring for patients with cancer in hospital? $\mathrm{Br}$ $J$ Cancer. 2007;97(4):472-478. doi:10.1038/sj.bjc.6603888

47. Crawford GB, Zambrano SC. Junior doctors' views of how their undergraduate clinical electives in palliative care influenced their current practice of medicine. Acad Med. 2015;90(3):338-344. doi:10.1097/ACM.0000000000000632

48. Abrão $\mathrm{M}$, Bensi $\mathrm{C}$, Gonçalves $\mathrm{M}$, Narahara $\mathrm{J}$, Otsuka $\mathrm{F}$. A medical student-staffed outpatient oncology clinic: A 10-year Brazilian experience. J Cancer Educ. 2008;23(1):63-64. doi:10. 1080/08858190701641321

49. Freiser ME, Desai DD, Azcarate PM, et al. Educational Value of a Medical Student-Led Head and Neck Cancer Screening Event. Otolaryngology-Head and Neck Surgery. 2016;154(4):638-644. doi:10.1177/0194599815626147

50. Fackrell FD. Medical Student-led Outpatient Clinics: improving Undergraduate Oncology Education. Clin Oncol. 2017;29(7): e140. doi:10.1016/j.clon.2017.02.001

51. Wilkerson L, Lee M, Hodgson CS. Evaluating Curricular Effects on Medical Students' Knowledge and Self-perceived Skills in Cancer Prevention. Acad Med. 2002;77(Supplement):S51. doi:10. 1097/00001888-200210001-00017

52. Wånggren K, Pettersson G, Gemzell-Danielsson K. Medical students learning the pelvic examination: evaluation of a clinical patient model. Acta Obstet Gynecol Scand. 2010;89(10): 1304-1309. doi:10.3109/00016349.2010.513425

53. Epner DE, Baile WF. Difficult Conversations: teaching Medical Oncology Trainees Communication Skills One Hour at a Time. Acad Med. 2014;89(4):578-584. doi:10.1097/ACM.0000000000 000177

54. Hogg ME, Besselink MG, Clavien P-A, Fingerhut A, Jeyarajah R. Training in Minimally Invasive Pancreatic Resections: a paradigm shift away from "See one, Do one, Teach one". HPB. 2017;19 (3):234-245. doi:10.1016/j.hpb.2017.01.016

55. Golden D, Stepaniak C, Chmura S. Radiation Oncology Self-Directed Dosimetry Workshops: AP/PA Spine, 3-Field Breast, and IMRT. MedEdPORTAL. 2012;8. doi:10.15766/ mep_2374-8265.9297

56. Reiss KA, Rangachari D, Cosgrove D, Wilky B, Donehower DR. Growing Pains: a Simulation-Based Curriculum for Improving the Transition to Hematology/ Oncology Fellowship. J Cancer Educ. 2017;32(3):496-502. doi:10.1007/s13187-015-0974-1
57. Head BA, Schapmire T, Earnshaw L, et al. Evaluation of an Interdisciplinary Curriculum Teaching Team-based Palliative Care Integration in Oncology. $J$ Cancer Educ. 2016;31 (2):358-365. doi:10.1007/s13187-015-0799-y

58. Uijtdehaage S, Hauer KE, Stuber M, Go VL, Rajagopalan S, Wilkerson L. Preparedness for Caring of Cancer Survivors: a Multi-Institutional Study of Medical Students and Oncology Fellows. J Cancer Educ. 2009;24(1):28-32. doi:10.1080/0885 8190802665260

59. Finlay, Maughan, Webster. A randomized controlled study of portfolio learning in undergraduate cancer education. Med Educ. 1998;32(2):172-176. doi:10.1046/j.1365-2923.1998.00160.x

60. Madan AK, Aliabadi-Wahle S, Babbo AM, Posner M, Beech DJ. Education of medical students in clinical breast examination during surgical clerkship. Am J Surg. 2002;184(6):637-640. doi:10. 1016/S0002-9610(02)01094-2

61. Gerling GJ, Weissman AM, Thomas GW, Dove EL. Effectiveness of a dynamic breast examination training model to improve clinical breast examination (CBE) skills. Cancer Detect Prev. 2003;27(6):451-456. doi:10.1016/j.cdp.2003.09.008

62. Lutgendorf-Caucig C, Kaiser PA, Machacek A, Waldstein C, Potter R, Vienna Summer L-SH. School on Oncology: how to teach clinical decision making in a multidisciplinary environment. BMC Med Educ Lond. 2017;17. doi:10.1186/s12909-017-0922-3

63. Jazieh AR, Henle K, Deloney LA, Savidge M, Fulper-Smith M, Nicholas R. The impact of a cancer education program on the knowledge base of participating students. $J$ Cancer Educ. 2001;16(1):8-11. doi:10.1080/08858190109528715

64. McKillip RP, Hahn OM, Bartkowiak B, et al. Implementation of a Novel Medical School Multidisciplinary and Interprofessional Oncology Curriculum: a Mixed Method Study. J Cancer Educ. 2019;34(1):50-55. doi:10.1007/s13187-017-1264-x

65. De Vries J, Szabó BG, Sleijfer DT. The educational yield of the international summer school "Oncology for Medical Students.". J Cancer Educ. 2002;17(3):115-120. doi:10.1080/088581902095 28817

66. Zaorsky NG, Malatesta TM, Den RB, et al. Assessing the value of an optional radiation oncology clinical rotation during the core clerkships in medical school. Int J Radiat Oncol Biol Phys. 2012;83(4):e465-e469. doi:10.1016/j.ijrobp.2012.01.058

67. Fromm-Haidenberger S, Pohl G, Widder J, et al. Vienna International Summer School on Experimental and Clinical Oncology for Medical Students: an Austrian Cancer Education Project. J Cancer Educ. 2010;25(1):51-54. doi:10.1007/s13187009-0011-3

68. Morgulis Y, Kumar R, Lindeman R, Velan GM. Impact on learning of an e-learning module on leukaemia: a randomised controlled trial. BMC Med Educ. 2012;12(1):36. doi:10.1186/ 1472-6920-12-36

69. Sneiderman CA, Hood AF, Patterson JW. Evaluation of an interactive computer video tutorial on malignant melanoma. J Biocommun. 1994;21(2):2-5.

70. Bishop TW, Gorniewicz J, Floyd M, Tudiver F, Odom A, Zoppi K. Innovative patient-centered skills training addressing challenging issues in cancer communications: using patient's stories that teach. Int J Psychiatry Med. 2016;51(4):357-366. doi:10.1177/0091217416659272

71. Mehta MP, Sinha P, Kanwar K, Inman A, Albanese M, Fahl W. Evaluation of Internet-based oncologic teaching for medical students. J Cancer Educ. 1998;13(4):197-202. doi:10.1080/088 58199809528546

72. Miedzybrodzka Z, Hamilton NM, Gregory H, et al. Teaching undergraduates about familial breast cancer: comparison of a computer assisted learning (CAL) package with a traditional tutorial approach. Eur J Hum Genet. 2001;9(12):953-956. doi:10. 1038/sj.ejhg.5200751 
73. Markova A, Weinstock MA, Risica P, et al. Effect of a Web-Based Curriculum on Primary Care Practice: basic Skin Cancer Triage Trial. Fam Med. 2014;11.

74. Mayer B, Ring C, Muche R, Rothenbacher D, SchmidtStraßburger U. Creating a blended learning module in an online master study programme in oncology. Educ Health. 2015;28 (1):101. doi:10.4103/1357-6283.161951

75. Barrett K, Mistry N, Hayter C, et al. The Effectiveness of the Ivan H. Smith Memorial Studentships Program on Encouraging Medical Students to Pursue a Career in Radiation Oncology. $J$ Cancer Educ. 2008;23(4):226-229. doi:10.1080/0885819080 2432992

76. Hirsch AE, Agarwal A, Rand AE, et al. Medical student mentorship in radiation oncology at a single academic institution: A 10-year analysis. Pract Radiat Oncol. 2015;5(3):163-168. doi:10.1016/j.prro.2014.08.005

77. Wisniewski WR, Fournier KF, Ling YK, et al. A focused curriculum in surgical oncology for the third-year medical students. J Surg Res. 2013;185(2):555-560. doi:10.1016/j.jss.2013.06.019

78. Tarkowski R, Kornafel KJ. Students' Scientific Society-How to Inspire Students and Help them to Become Oncologists? A Tutor's Perspective. J Cancer Educ. 2014;29(1):11-13. doi:10.1007/s13187-013-0587-5

79. Agarwal A, DeNunzio NJ, Ahuja D, Hirsch AE. Beyond the standard curriculum: a review of available opportunities for medical students to prepare for a career in radiation oncology. Int J Radiat Oncol Biol Phys. 2014;88(1):39-44. doi:10.1016/j. ijrobp.2013.08.003

80. Agarwal A, Shah A, Byler S, Hirsch AE. Cultivating Interest in Oncology Through a Medical Student Oncology Society. J Cancer Educ. 2017;32(1):31-34. doi:10.1007/s13187-015-0902-4

81. DeNunzio N, Parekh A, Hirsch AE. Mentoring Medical Students in Radiation Oncology. J Am Coll Radiol. 2010;7(9):722-728. doi:10.1016/j.jacr.2010.03.018

82. Golden DW, Raleigh DR, Chmura SJ, Koshy M, Howard AR. Radiation Oncology Fourth-Year Medical Student Clerkships: A Targeted Needs Assessment. Int J Radiat Oncol. 2013;85 (2):296-297. doi:10.1016/j.ijrobp.2012.05.012

83. Zaorsky NG, Malatesta TM, Showalter TN, et al. Impact of a Radiation Oncology Elective on the Careers of Young Physicians: update on a Prospective Cohort Study. Int J Radiat Oncol. 2013;86(2):214-215. doi:10.1016/j.ijrobp.2013.02.001

84. Mayes J, Davies S, Harris A, Wray E, Dark GG. Impact of a 2-Week Oncology Placement on Medical Students' Perception of Cancer. J Cancer Educ. 2018;33(1):174-179. doi:10.1007/ s13187-016-1101-7

85. Geller AC, Prout MN, Miller DR, et al. Evaluation of a Cancer Prevention and Detection Curriculum for Medical Students. Prev Med. 2002;35(1):78-86. doi:10.1006/pmed.2002.1044

86. Cecilio-Fernandes D, Aalders WS, de Vries J, Tio RA. The Impact of Massed and Spaced-Out Curriculum in Oncology Knowledge Acquisition. J Cancer Educ. 2018;33(4):922-925. doi:10.1007/s13187-017-1190-y

87. Mann BD, Sachdeva A, Neiman L, Nielan B, Rovito M, Damsker J. Teaching medical students by role playing: A model for integrating psychosocial issues with disease management. $J$ Cancer Educ. 1996;11(2):65-72. doi:10.1080/0885819960952 8398

88. Henderson P, Johnson M. Assisting medical students to conduct empathic conversations with patients from a sexual medicine clinic. Med Teach. 2000;22:6. doi:10.1080/01421590050175578

89. Neppala P, Sherer MV, Larson G, et al. An interactive contouring module improves engagement and interest in radiation oncology among preclinical medical students: results of a randomized trial. Pract Radiat Oncol. 2018;8(4):190-198. doi:10.1016/j.prro.20 18.01.001
90. Belfrage A, Grotmol KS, Lien L, Moum T, Wiese RV, Tyssen R. Medical school predictors of later perceived mastery of clinical work among Norwegian doctors: a cohort study with 10-year and 20-year follow-up. BMJ Open. 2017;7(9):9. doi:10.1136/bmjopen-2016-014462

91. Mitchell CM, Epstein-Peterson ZD, Bandini J, et al. Developing a Medical School Curriculum for Psychological, Moral, and Spiritual Wellness: student and Faculty Perspectives. J Pain Symptom Manage. 2016;52(5):727-736. doi:10.1016/j.jpainsymman.2016.05.018

92. Morgan H, McLean K, Chapman C, Fitzgerald J, Yousuf A, Hammoud M. The flipped classroom for medical students. Clin Teach. 2015;12(3):155-160. doi:10.1111/tct.12328

93. Turner S, Seel M, Trotter $\mathrm{T}$, et al. Defining a Leader Role curriculum for radiation oncology: A global Delphi consensus study. Radiother Oncol. 2017;123(2):331-336. doi:10.1016/j. radonc.2017.04.009

94. Janssen A, Shaw T, Bradbury L, et al. A mixed methods approach to developing and evaluating oncology trainee education around minimization of adverse events and improved patient quality and safety. BMC Med Educ. 2016:16. doi:10.1186/s12909-016-0609-1

95. De Visser M, Fluit C, Timmer-Bonte J, Ottevanger P, Verhagen C, Klaassen T. Teaching adjuvant endocrine breast cancer treatment to medical students. Neth J Med. 2013;71(4):5.

96. Eid A, Hsieh P, Shah P, Wolff R. Cross-sectional longitudinal study of the academic half-day format in a hematology-oncology fellowship training program. BMC Med Educ. 2015;15(1):139. doi:10.1186/s12909-015-0418-y

97. Khorana A, Shayne M, Korones D. Can Literature Enhance Oncology Training? A Pilot Humanities Curriculum. J Clin Oncol. 2011;29(4):468-471. doi:10.1200/JCO.2010.33.3617

98. Pavlidis N, Alba E, Berardi R, et al. The ESMO/ASCO Global Curriculum and the evolution of medical oncology training in Europe. ESMO Open. 2016;1:1. doi:10.1136/esmoopen-2015000004

99. Dennis KEB, Duncan G. Radiation Oncology in Undergraduate Medical Education: A Literature Review. Int J Radiat Oncol. 2010;76(3):649-655. doi:10.1016/j.ijrobp.2009.08.038

100. Payne S, Burke D, Mansi J, et al. Discordance between cancer prevalence and training: a need for an increase in oncology education. Clin Med. 2013;13(1):50-56. doi:10.7861/clinmedicine. $13-1-50$

101. Zumberg MS, Broudy VC, Bengtson EM, Gitlin SD. Preclinical Medical Student Hematology/Oncology Education Environment. $J$ Cancer Educ. 2015;30(4):711-718. doi:10.1007/s13187-0140778-8

102. Hirsch A, DeNunzio N, Levin-Epstein R, Bishop P. In Regards to Dennis and Duncan: radiation Oncology in Undergraduate Medical Education: A Literature Review (Int J Radiat Oncol Biol Phys 2010;76:649-655). Int J Radiat Oncol Biol Phys. 2010;78(2):639. doi:10.1016/j.ijrobp.2010.03.041

103. Amgad M, Shash E, Gaafar R. Cancer education for medical students in developing countries: where do we stand and how to improve? Crit Rev Oncol Hematol. 2012;84(1):122-129. doi:10.1016/j.critrevonc.2012.01.003

104. Horowitz R, Gramling R, Quill T. Palliative care education in US medical schools. Med Educ. 2014;48(1):59-66. doi:10.1111/ medu. 12292

105. Ross D, Fraser H, Kutner J. Institutionalization of a Palliative and End-of-Life Care Educational Program in a Medical School Curriculum. J Palliat Med. 2001;4(4):512-518. doi:10.1089/ 109662101753381683

106. DeNunzio N, Hirsch AE, et al. The Need for a Standard, Systematic Oncology Curriculum for U.S. Medical Schools. Acad Med. 2011;86(8):921. doi:10.1097/ACM.0b013e3182223 $06 \mathrm{e}$ 
107. Zaorsky NG, Shaikh T, Handorf E, et al. What Are Medical Students in the United States Learning About Radiation Oncology? Results of a Multi-Institutional Survey. Int J Radiat Oncol. 2016;94(2):235-242. doi:10.1016/j.ijrobp.20 15.10.008

108. Cheung WY, Fishman PN, Verma S. Oncology education in Canadian undergraduate and postgraduate training programs. $J$ Cancer Educ. 2009;24(4):284-290. doi:10.1080/0885819090 2973143

109. Nicholls L, Bravery B, Chelvarajah R, et al. The status of radiation oncology teaching in Australian and New Zealand medical schools. J Med Imaging Radiat Oncol. 2018;62(6):828-834. doi:10.1111/1754-9485.12788

110. George M, Mandaliya H, Prawira AA. A Survey of Medical Oncology Training in Australian Medical Schools: pilot Study. JMIR Medical Educ. 2017;3(2):2. doi:10.2196/ mededu. 7903

111. Matkowski R, Szelachowska J, Szewczyk K, Staszek-Szewczyk U, Kornafel J. Improvements in Undergraduate Oncology Education Introduced at Polish Medical Universities Between 2004 and 2010 Under Poland's "National Program for Combating Neoplastic Diseases". J Cancer Educ. 2014;29 (3):428-433. doi:10.1007/s13187-014-0633-y

112. Eychmüller S, Forster M, Gudat H, Lütolf UM, Borasio GD. Undergraduate palliative care teaching in Swiss medical faculties: a nationwide survey and improved learning objectives. BMC Med Educ. 2015;15. doi:10.1186/s12909-015-0485-0
113. Samalavicius NE, Mineikyte R, Janulionis E, Liutkeviciutenavickiene J, Atkocius V. Postgraduate Cancer Education and Training in Lithuania: harmonization According to the EU Rules. Journal of Cancer Education. 2015;30(2):360-366. doi:10. 1007/s13187-014-0737-4

114. Cecilio-Fernandes D, Aalders WS, Bremers AJA, Tio RA, de Vries J. The Impact of Curriculum Design in the Acquisition of Knowledge of Oncology: comparison Among Four Medical Schools. J Cancer Educ. 2018;33(5):1110-1114. doi:10.1007/s13 187-017-1219-2

115. Lehto JT, Hakkarainen K, Kellokumpu-Lehtinen P-L ST. Undergraduate curriculum in palliative medicine at Tampere University increases students' knowledge. BMC Palliat Care. 2017;16. doi:10.1186/s12904-016-0182-8

116. Nakamura Y, Takamiya Y, Saito M, et al. A survey of palliative medicine education in Japan's undergraduate medical curriculum. BMC Palliat Care. 2017:16. doi:10.1186/s12904-017-0212-1

117. Ratanakaaew A, Khemapech N, Laurujisawat P. Palliative Care Education in Gynecologic Oncology: A Survey of Gynecologic Oncologists and Gynecologic Oncology Fellows in Thailand. Asian Pac J Cancer Prev. 2015;16(15):6331-6334. doi:10.7314/ apjcp.2015.16.15.6331

118. Soliman A, Nasser S, El-Hattab O, Sobeih T, Chamberlain R. Cancer education in medical, nursing, and pharmacy schools in Egypt: features applicable to other countries. J Cancer Educ. 2003;18(1):12-14. doi:10.1207/s15430154jce1801_8
Advances in Medical Education and Practice

\section{Publish your work in this journal}

Advances in Medical Education and Practice is an international, peerreviewed, open access journal that aims to present and publish research on Medical Education covering medical, dental, nursing and allied health care professional education. The journal covers undergraduate education, postgraduate training and continuing medical education including emerging trends and innovative models linking education, research, and health care services. The manuscript management system is completely online and includes a very quick and fair peer-review system. Visit http://www.dovepress.com/testimonials.php to read real quotes from published authors. 